\title{
Rheumatoid trigger wrist
}

\author{
G. Minetti ${ }^{1}$, B. Bartolini ${ }^{2}$, G. Garlaschi ${ }^{3}$, E. Silvestri ${ }^{4}$, M. A. Cimmino ${ }^{5}$ \\ ${ }^{1}$ Division of Radiology, IRCCS S. Martino Hospital, Genova, Italy; \\ ${ }^{2}$ La Pitié-Salpêtrière Hospital, Paris, France; ${ }^{3}$ Division of Radiology, University of Genova, Italy; \\ ${ }^{4}$ Division of Radiology, International Evangelical Hospital, Genova; ${ }^{5}$ Research Laboratory and Academic \\ Division of Clinical Rheumatology, Department of Internal Medicine, University of Genova, Italy
}

A $48-$ 48 -year-old man with a 10 -year history of seropositive, nodular rheumatoid arthritis (RA) presented with numbness in the right median nerve cutaneous area exacerbated by flexion of the fingers, which movement was associated with a snapping felt on the volar part of the wrist. His RA was clinically well controlled with an association of methotrexate $(15 \mathrm{mg}$ weekly) and leflunomide (20 mg daily), prednisone (5 mg daily), and NSAIDs.

At the time of examination, DAS28 was 2.56 .

Flexion and extension of all fingers were difficult to initiate, and were associated with a palpable click at the wrist. MRI, on a dedicated 0.2 T MRI unit (T1 weighted
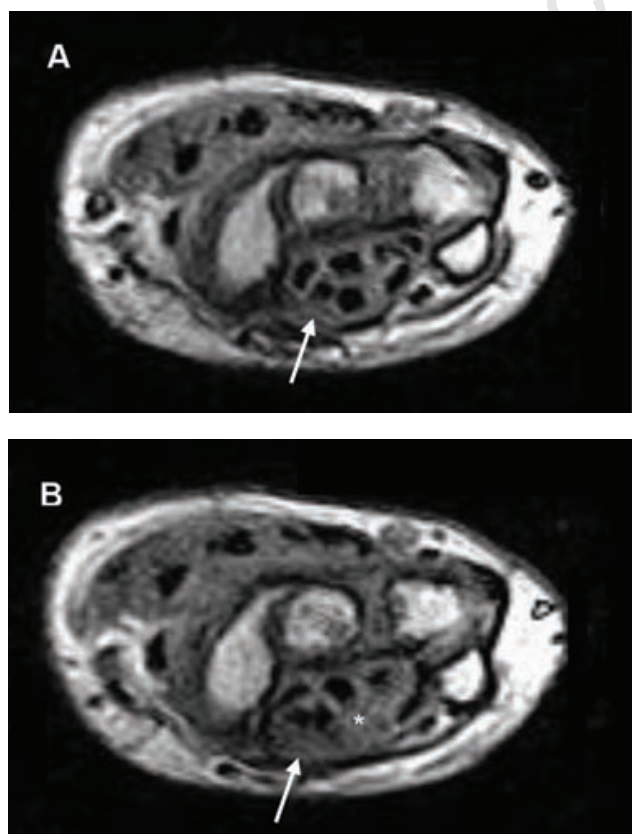

Figure 1 spin echo sequence, repetition time/echo time 460/24, slice thickness $3 \mathrm{~mm}$; figure 1 ), and US with a high frequency linear array (Mhz 13-4) (Figure 2) were performed on the wrist during finger extension (A) and flexion (B).

Both showed chronic tenosynovitis of the flexor tendons. The synovial tissue was displaced proximally during finger flexion (asterisk, figure 1B and dotted area in figure 2), impinged on the carpal tunnel, and caused displacement and compression of the median nerve (arrow) (FS: flexor digitorum superficialis; FP: flexor digitorum profundus; CB: carpal bones.).

The intrinsic ligaments were preserved; no dislocation of the carpal bones on the sag-
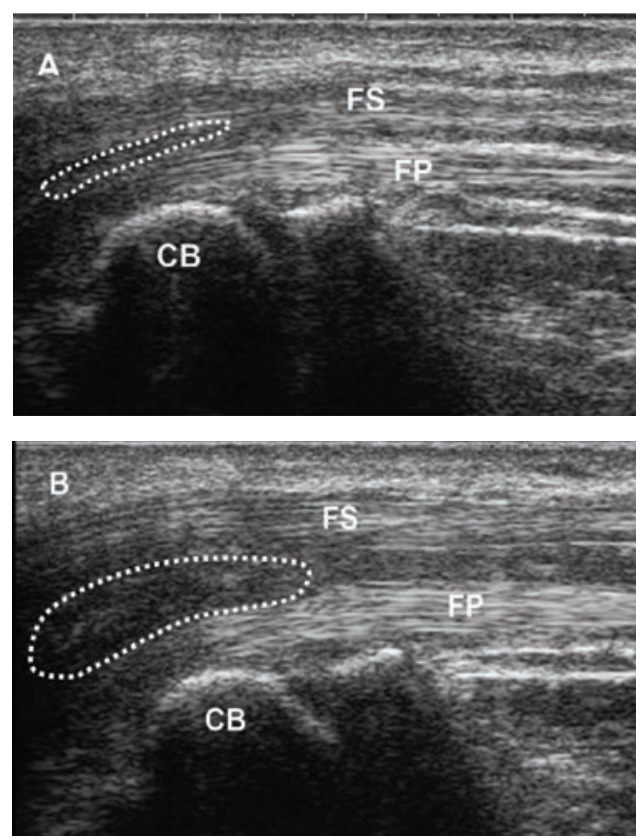

Figure 2 $\overline{\text { Corresponding author: }}$ Marco A. Cimmino Research Laboratory and Academic Division of Clinical Rheumatology, Department of Internal Medicine, University of Genova, Italy E-mail: cimmino@unige.it 
ittal plane was observed. Trigger wrist can occur in several conditions, such as lipoma, fibroma, anomalous skeletal muscles, tophi (1), synovitis of the carpal tunnel (2), pigmented villonodular synovitis and rheumatoid nodules (3).

The underlying mechanism is inadequacy of the carpal tunnel size to accomodate its contents.

The authors declare they have not conflicts of interest.

\section{REFERENCES}

1. Park IJ, Lee YM, Rhee SK, Song SW, Kim HM, Choi KB. Trigger wrist. Clin Orthop Surg 2015; 7: 523-6.

2. Rand B, McBride TJ, Dias RG. Combined triggering at the wrist and severe carpal tunnel syndrome caused by gouty infiltration of a flexor tendon. J Hand Surg Eur Vol 2010; 35 : 240-2.

3. Park IJ, Lee YM, Kim HM, Lee JY, Roh YT, Park CK, Kang SH. Multiple etiologies of trigger wrist. J Plast Reconstr Aesthet Surg 2015 Oct 30. pii: S1748-6815(15)00514-8. doi: 10.1016/j.bjps.2015.10.030. [Epub ahead of print]. 